\title{
Low-frequency ultrasound enhances vascular endothelial growth factor expression, thereby promoting the wound healing in diabetic rats
}

\author{
LANG CHEN $^{1}$, QIAN ZHENG ${ }^{2}$, XIANZHUO CHEN $^{1}$, JUN WANG $^{1}$ and LAN WANG $^{1}$ \\ ${ }^{1}$ Department of Burns and Plastic, Affiliated Hospital of North Sichuan Medical College; \\ ${ }^{2}$ Department of Clinical Medicine, North Sichuan Medical College, Nanchong, Sichuan 637000, P.R. China
}

Received September 28, 2018; Accepted August 16, 2019

DOI: $10.3892 / \mathrm{etm} .2019 .8051$

\begin{abstract}
Diabetes is a chronic metabolic disease with a high prevalence worldwide, which typically delays or impairs wound healing, potentially causing death. Low-frequency ultrasound treatment promotes the repair of various injuries and may promote wound healing. The aim of the present study was to determine whether low-frequency ultrasound can accelerate wound healing, as well as investigate its effects on the expression of vascular endothelial growth factor (VEGF), transforming growth factor (TGF)- $\beta 1$, interleukin (IL)- 6 and tumor necrosis factor (TNF)- $\alpha$ in diabetic rats. A total of 45 Wistar rats were intraperitoneally injected with $1 \%$ streptozocin following intraperitoneal injection of pentobarbital sodium anesthesia. Subsequently an incision wound was created in the skin of back. The area of the wound was recorded to calculate the rate of wound healing. The expression of VEGF and TGF- $\beta 1$ was determined via immunohistochemical analysis and their mRNA and protein levels were measured via reverse transcription-quantitative PCR analysis. The results revealed that when compared with the control group, low-frequency ultrasound treatment significantly increased wound healing rate in diabetic rats and markedly increased the mRNA and protein levels of VEGF and TGF- $\beta 1$. US treatment also reduced the mRNA and protein levels of TNF- $\alpha$ and IL-6. In conclusion, the results of the present study indicated that low-frequency ultrasound promotes the expression of VEGF and TGF- $\beta 1$, and inhibits the expression of IL- 6 and TNF- $\alpha$, thereby promoting wound healing in diabetic rats.
\end{abstract}

Correspondence to: Professor Qian Zheng, Department of Clinical Medicine, North Sichuan Medical College, 234 Fujiang Road, Nanchong, Sichuan 637000, P.R. China

E-mail: 583319649@qq.com

Key words: low-frequency ultrasound, vascular endothelial growth factor, wound healing, diabetic rats

\section{Introduction}

Diabetes is a highly prevalent chronic metabolic disease, affecting >400 million individuals worldwide, which often causes delayed or impaired wound healing (1), representing a major health concern and a heavy socioeconomic burden. According to incomplete statistics, $20 \%$ of patients with diabetes suffer from foot ulcers and $>20 \%$ of patients require amputations (2-4). The rate of amputation is markedly higher among diabetic patients compared with the general population $(2,5)$. Wound healing in diabetes is delayed and several therapeutic approaches are ineffective $(6,7)$. The etiology of diabetic foot ulcers is complex. Age, sex, vascular disease, infection, blood pressure and smoking may affect the progression of diabetic foot ulcers, and the majority of studies have reported that the pathogenesis of diabetic foot ulcers is closely associated with ischemia, neuropathy and infection $(8,9)$. Angiopathy (9), particularly in vascular diseases of the lower extremities, is the earliest and most common complication leading to the development of diabetic foot ulcers. Additionally, diabetic microangiopathy is a risk factor for diabetic foot. Due to long-term hyperglycemia, diabetic patients accumulate a large number of advanced glycation end-products in vivo, resulting in endothelial cell damage and apoptosis, thickening of the intimal vascular wall, luminal stenosis or obstruction (10). Furthermore, endothelial cell damage promotes platelet adhesion, erythrocyte aggregation and microthrombosis, leading to insufficient irrigation of the affected limb, with ensuing ischemia, hypoxia and eventually diabetic ulcer formation or aggravation of diabetic foot ulcers (10-12).

Wound healing is a complex biological process that may be divided into three stages: Inflammatory response, cell differentiation and proliferation, and tissue repair (13). Numerous factors may delay the wound healing process, including the inhibition of cytokine production by fibroblasts and inflammatory cells. During the early stages of wound healing, the overexpression of inflammatory factors, such as interleukin (IL)-6 and tumor necrosis factor (TNF)- $\alpha(14,15)$, severely impairs the formation of granulation tissue and further delays wound healing. However, a number of studies have revealed that growth factors, including vascular endothelial growth factor (VEGF) $(2,4,16)$, epidermal growth factor $(17,18)$ 
and transforming growth factor- $\beta$ (TGF- $\beta)(19,20)$, serve an important role in the promotion of wound healing.

A number of treatment methods have been developed to promote wound healing in diabetic foot ulcers, including vascular reconstruction, negative pressure treatment, stem cell transplantation therapy, hyperbaric oxygen therapy and tissue engineering technology, among others (21-25). Although these treatment methods have improved the wound healing of diabetic foot ulcers, their efficacy is unsatisfactory. Hence, an increasing number of topical treatments have been developed, particularly involving debridement methods including surgical, biological, and dressing debridement, and have been widely applied for the treatment of diabetic patients in the clinical setting (26). Debridement eliminates necrotic tissue, decreases chronic inflammatory factor levels, increases cytokine secretion, promotes the growth of granulation tissue and reduces the absorption of toxins during necrosis tissue decomposition and degradation (27-29). Therefore, debridement is widely used in the clinical setting to promote wound healing in patients with diabetes (30). In addition, ultrasonic debridement may promote the repair of various injuries, including those of the bone, tendon, muscle, cartilage and ligament (31-33).

The aim of the present study was to determine whether low-frequency ultrasound accelerates wound healing and tissue regeneration in diabetic rats, and to investigate its effects on the expression of VEGF, TGF- $\beta 1$, IL- 6 and TNF- $\alpha$.

\section{Materials and methods}

Animals. A total of 45 female Wistar rats, weighing 250-300 g, were purchased from the Laboratory Animal Center of North Sichuan Medical College. They were fed for 1 week at $18-2^{\circ} \mathrm{C}$ in $12 \mathrm{~h}$ light/dark cycle with access to food and water ad libitum, and a humidity of 50-60\%. The animals were handled humanely according to the guidelines provided in the Guide for the Care and Use of Laboratory Animals, published by the National Institute of Health (34). The rats were anesthetized by intraperitoneal administration of $2.25 \%$ pentobarbital sodium $(45 \mathrm{mg} / \mathrm{kg})$. All animal procedures were approved by the Ethics Committee of Affiliated Hospital of North Sichuan Medical College [approval no. 2016ER(A)022].

Streptozotocin (STZ)-induced diabetic rat model and experimental groups. A diabetic rat model was established in all Wistar rats using STZ, as described previously (35-37). Rats were intraperitoneally injected with $1 \%$ STZ $(60 \mathrm{mg} / \mathrm{kg})$ following anesthesia. A total of 1 week after STZ injection, the blood glucose levels of all rats were $>16.7 \mathrm{mmol} / \mathrm{l}$. Rats were subsequently placed in a prone position on a fixed plate, where a circular area $(3.0 \mathrm{~cm}$ in diameter) was marked on the skin of the back. A skin incision was created and cleaned with iodine. The diabetic animals were then randomly divided into three groups $(n=15)$ according to the different treatments administered: the untreated control group; the ultrasound (US) treatment group and the common treatment group. In rats of the US group, the wound was cleaned with normal saline and treated with low-frequency US (frequency, $1 \mathrm{MHz}$; sound intensity, $1.0 \mathrm{~W} / \mathrm{cm}^{2}$ ) for $15 \mathrm{~min}$. The working sound intensity range of low-frequency US is adjustable from $0.1-1.1 \mathrm{~W} / \mathrm{cm}^{2}$, with a frequency of $1 \mathrm{MHz}$ and a repetition frequency of $1 \mathrm{KHz}$ with continuous waves, accounting for $20 \%$ of the air ratio. The skin wound was then irradiated with an US sound intensity of $1.0 \mathrm{~W} / \mathrm{cm}^{2}$ once per day for 21 days. The sterile head of the ultrasound machine was connected to the ultrasonic debridement machine, with a saline bag used as the washing solution. When atomized water drops appeared on the machine head subsequent to first use, the front of the machine head was tilted to contact the wound surface at a $45^{\circ}$ angle. The irradiated wound surface was then moved at a constant and slow speed. After horizontal scanning, the irradiated wound surface was vertically scanned to ensure irradiation of all wound surfaces. In the common treatment group, the wound was cleaned with normal saline alone once per day (35-37).

Estimation of the wound healing rate. All rats were observed on day 7, 14 and 21 after wound formation. The area of the wound was recorded to calculate the rate of wound healing as follows: Wound healing rate=(1-remaining-wound area/initial wound area) $\mathrm{x} 100 \%$ (38).

Histological analysis. A biopsy sample was obtained from the wound edge on day 7,14 and 21 to determine the pathological changes occurring within the wound. Part of the biopsy specimens was fixed in $4 \%$ paraformaldehyde at $4^{\circ} \mathrm{C}$ for $48 \mathrm{~h}$, embedded in paraffin sectioned $(4 \mu \mathrm{m})$ and stained with hematoxylin for 3-8 $\mathrm{min}$ and eosin for 1-3 $\mathrm{min}(\mathrm{H} \& \mathrm{E})$ at room temperature to examine the pathological changes. The remaining part of the tissue was frozen at $-70^{\circ} \mathrm{C}$ to extract total RNA from rat skin.

Immunohistochemical (IHC) analysis. IHC semi-quantification analysis was performed as described previously (39), using a horseradish peroxidase-3,3'-diaminobenzidine (HRP-DAB) staining kit (Beyotime Institute of Biotechnology). Tissue sections from the different groups were blocked by $3 \% \mathrm{H} 2 \mathrm{O} 2$ at room temperature for $15 \mathrm{~min}$, and then incubated with the following primary antibodies for $1 \mathrm{~h}$ : anti-rabbit VEGF (Abcam; cat. no. ab11939, 1:100) and anti-rabbit TGF- $\beta 1$ (Abcam; cat. no. ab92486; $1: 100)$ at $4^{\circ} \mathrm{C}$. Each antibody was diluted in PBS. Subsequently, samples were incubated with biotinylated goat anti-rabbit antibodies (Abcam; cat. no. ab6721; 1:100) for $30 \mathrm{~min}$ at room temperature. The specific binding of the secondary to primary antibodies was visualized using HRP for the enzymatic conversion of the chromogenic substrate DAB into a brown precipitate. The sections were mounted, cleared, cover-slipped, and examined under a fluorescence microscope (magnification, x100). The scale bar was $100 \mu \mathrm{m}$.

Reverse transcription-quantitative $(R T-q) P C R$. Total RNA was extracted from rat skin using the TRIzol ${ }^{\circledR}$ reagent (Thermo Fisher Scientific, Inc.) according to the manufacturer's protocol. Samples were then reverse transcribed using the Bestar ${ }^{\mathrm{TM}}$ qPCR RT kit (Takara Bio, Inc.). The RT conditions were $37^{\circ} \mathrm{C}$ for $15 \mathrm{~min}$ and $98^{\circ} \mathrm{C}$ for $5 \mathrm{~min}$. qPCR was performed using the ABI Prism 7500 Real-Time PCR System (Applied Biosystems; Thermo Fisher Scientific, Inc.) with the SYBR ${ }^{\circledR}$ Premix Ex $\mathrm{Taq}^{\mathrm{TM}}$ kit (Takara Bio, Inc.). PCR amplification conditions were as follows: denaturing at $95^{\circ} \mathrm{C}$ for $30 \mathrm{sec}$, followed by 40 cycles of $95^{\circ} \mathrm{C}$ for $5 \mathrm{sec}$ and $60^{\circ} \mathrm{C}$ for $1 \mathrm{~min}$. GAPDH was 
A
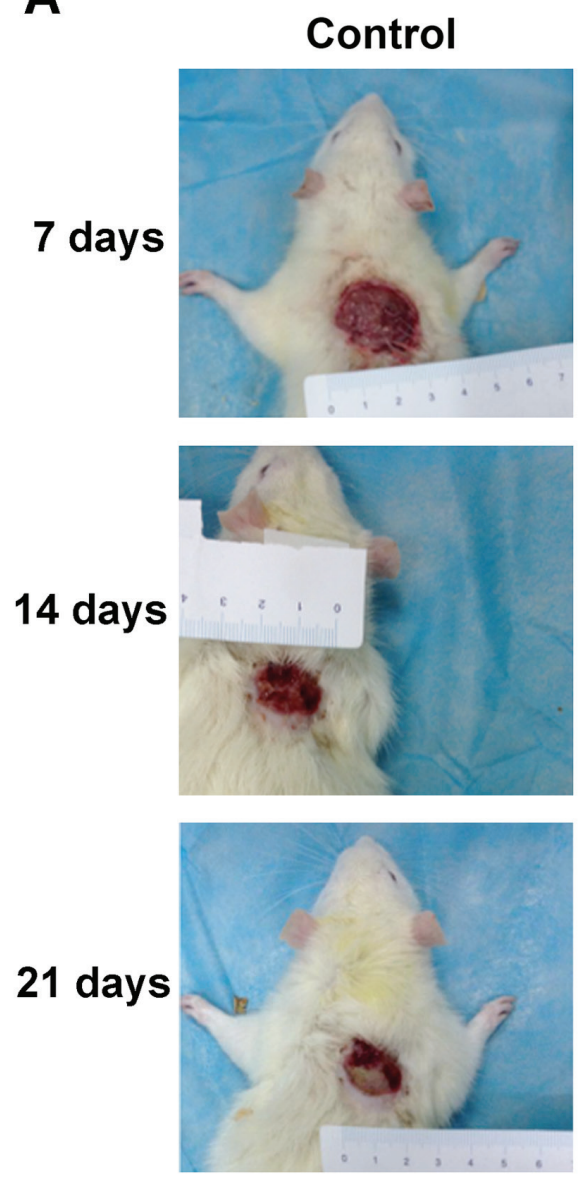

Common treatment
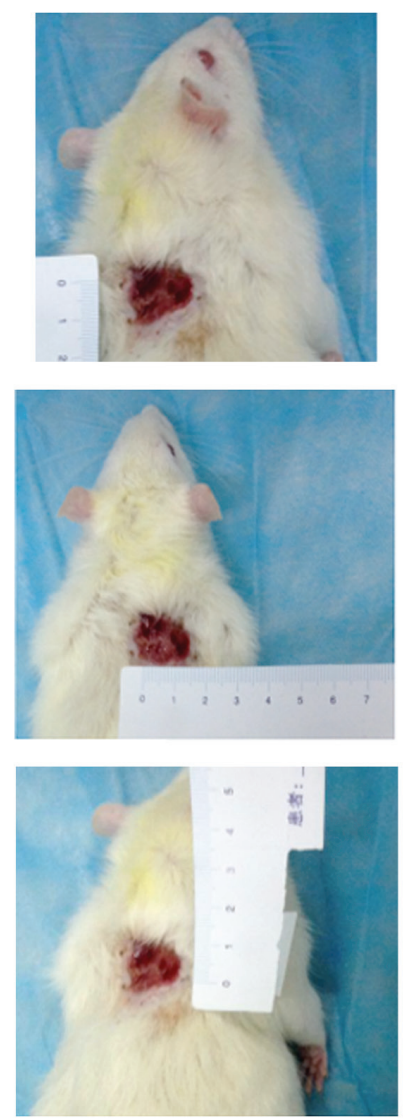

US. treatment
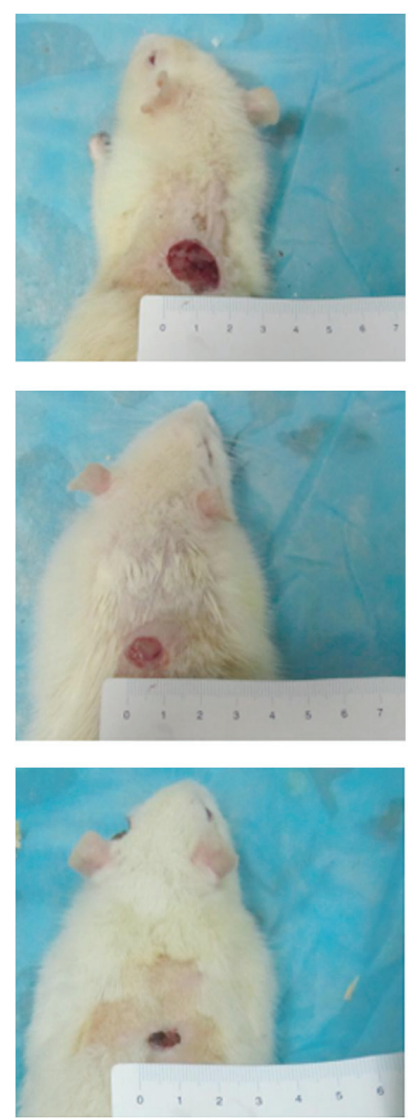

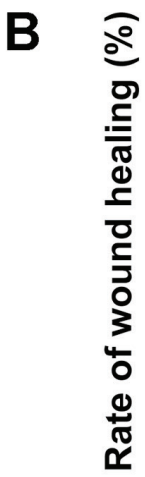

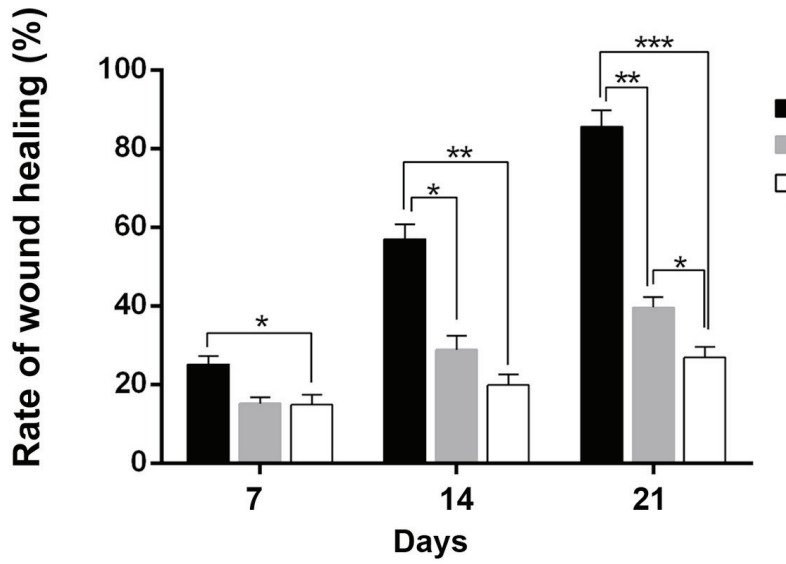

Ultrasound treatment

Common treatment

Control

Figure 1. Wound healing of diabetic rats in each group after treatment for different periods. (A) The wound size was markedly reduced in the US treatment group compared with the control group. (B) The wound healing rate in the US treatment group was increased compared with the control group at the 7th day. As the treatment time prolonged, the difference of wound healing rate became more marked between the US and control group. ${ }^{*} \mathrm{P}<0.05,{ }^{* * *} \mathrm{P}<0.01$ and ${ }^{* * *} \mathrm{P}<0.001$ as indicated. US, ultrasound

used for normalization. Data are presented as fold difference and were calculated using the $2^{-\Delta \Delta \mathrm{Cq}}$ relative expression method (40). The primers used were as follows: VEGF forward 5'-TCCAGGAGTACCCCGATGA-3' and reverse, 5'-CTCCGC TCTGAACAAGGCT-3'; TGF- $\beta 1$ forward 5'-TAAGGCTCG CCAGTCCCC-3' and reverse, 5'-GGTTTTGTCATAGAT TGCGTTGTT-3'; TNF- $\alpha$ forward 5'-CTTCTCATTCCTGCT CGTGG-3' and reverse, 5'-TCCGCTTGGTGGTTTGC-3'; IL-6 forward, 5'-GCCTTCTTGGGACTGATGTTG-3' and reverse, 5'-GCTCTGAATGACTCTGGCTTTG-3'; GAPDH forward, 5'-TGAACGGGAAGCTCACTGG-3' and reverse, 5'-TCCACCACCCTGTTGCTGTA-3'.

Western blotting. Total protein was extracted from cells using RIPA lysis buffer (Beyotime Institute of Biotechnology) and determined using a bicinchoninic acid assay kit (Beyotime Institute of Biotechnology) in accordance with the manufacturer's protocol. Subsequently, $20 \mathrm{mg}$ of the cell lysate was separated via 10\% SDS-PAGE and transferred to PVDF membranes (EMD Millipore). The membranes were 

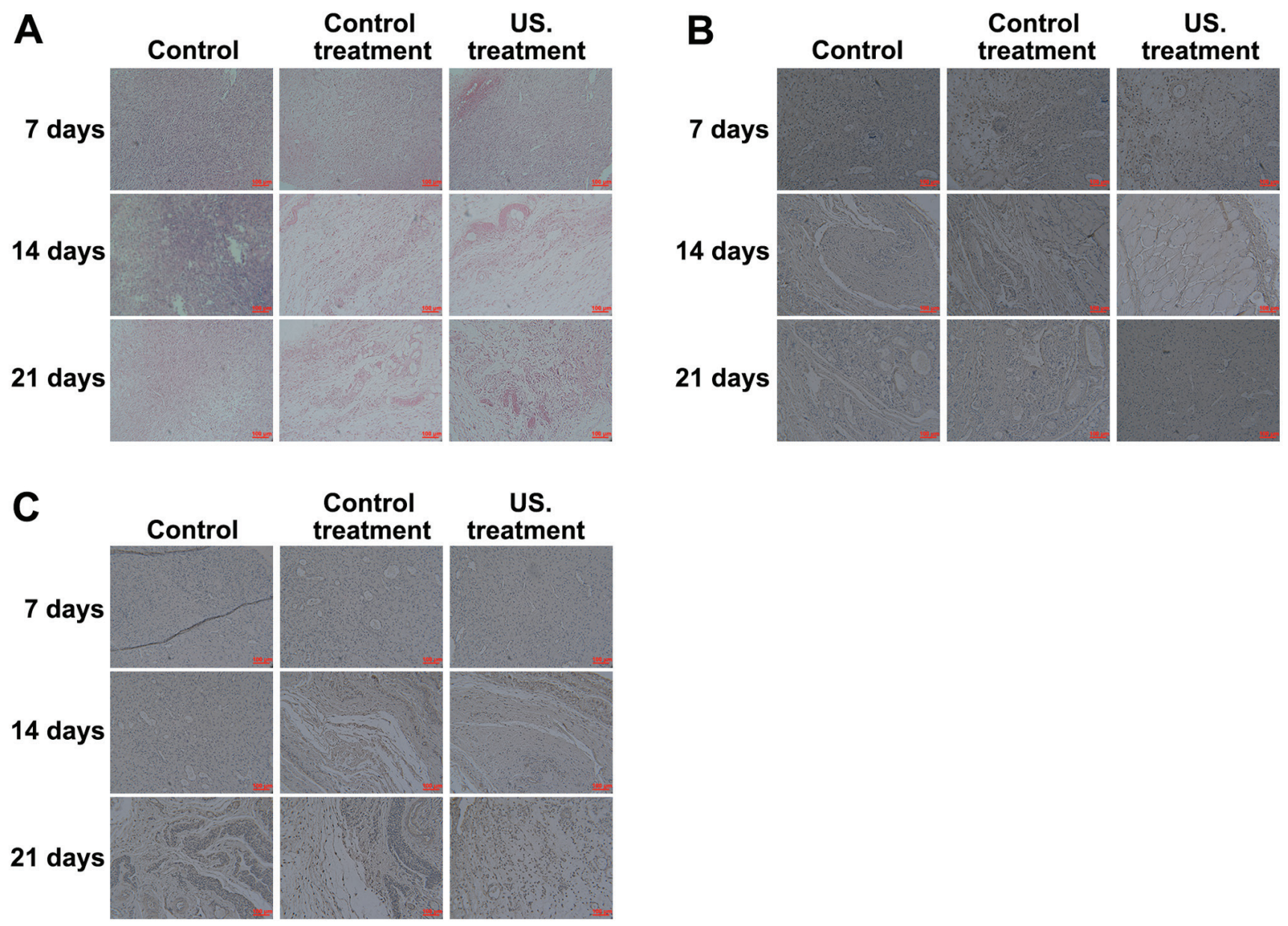

Figure 2. Histological and IHC analysis of the different groups. (A) Histological staining was performed to investigate the pathological changes occurring in the wound during the healing process. And the red arrow indicates collagen fibers, the blue arrow indicates fibroblasts, and the green arrow indicates neovascularization. IHC analysis indicated that (B) VEGF and (C) TGF- $\beta 1$ expression significantly increased in the US group compared with the control group. IHC, immunohistochemistry; US, ultrasound.

then blocked with $5 \%$ bovine serum albumin (Sigma-Aldrich; Merck KGaA) for $2 \mathrm{~h}$ at room temperature and incubated with the following primary antibodies obtained from Abcam overnight at $4^{\circ} \mathrm{C}$ : Anti-rabbit VEGF (Abcam; cat. no. ab11939; 1:500), anti-rabbit TGF- $\beta 1$ (Abcam; cat. no. ab92486; 1:1,000), anti-mouse TNF- $\alpha$ (Abcam; cat. no. ab9739; 1:1,000), anti-rabbit IL-6 (Abcam; cat. no. ab208113; 1:500) and anti-rabbit GAPDH (Abcam; cat. no. ab9385; 1:1,000). The immune complexes were then immunoblotted with horseradish peroxidase-conjugated anti-mouse or anti-rabbit IgG antibodies (Beijing ComWin Biotech Co., Ltd; 1:2,000). Immunodetection was performed using enhanced chemiluminescence reagents (Fdbio Science) by Image J 1.8.0 (National Institutes of Health).

Statistical analysis. Data were analyzed using SPSS 23.0 software (IBM Corp.), and were presented as the mean \pm standard deviation. Data were analyzed using an unpaired Student's t-test and one-way ANOVA with Bonferroni's post-hoc test. $\mathrm{P}<0.05$ was considered to indicate a statistically significant difference.

\section{Results}

Low-frequency US treatment accelerates wound healing in diabetic rats. After each post-operative treatment, the width of the wound was measured every 7 days, and the rate of wound healing was calculated with the aforementioned formula. The results demonstrated that, compared with the control group, the size of the wound area was significantly decreased in the US treatment group (Fig. 1A). As presented in Fig. 1B, the wound healing rate in the US treatment group was higher compared with the control $(25.12 \pm 2.06$ vs. $14.89 \pm 2.53 \%$; $\mathrm{P}<0.05)$ on the 7 th day. However, as the treatment time was prolonged, the difference in wound healing rate became markedly higher between the US treatment group and the control group (14th day, $56.98 \pm 3.76$ vs. $19.91 \pm 2.72 \%$; $\mathrm{P}<0.01 ; 21$ st day, $85.62 \pm 4.16$ vs. $26.89 \pm 2.64 \%$; $\mathrm{P}<0.001)$. In addition, the wound healing rate in the US treatment group was higher compared with the common treatment group at day 7, 14 and 21 post-treatment (14th day, 56.98 \pm 3.76 vs. $28.86 \pm 3.52 \% ; \mathrm{P}<0.05$, 21 st day, $85.62 \pm 4.16$ vs. $39.63 \pm 2.54 \%$; $\mathrm{P}<0.01)$. Furthermore, the wound healing rate of diabetic rats treated with normal saline for 21 days was significantly higher compared with the control group (39.63 \pm 2.54 vs. $26.89 \pm 2.64 \%$; $\mathrm{P}<0.05)$. The results indicated that low-frequency US treatment accelerates wound healing in diabetic rats.

Histological and IHC analysis. To determine the effects of low frequency US treatment on diabetic rat wound healing, $\mathrm{H} \& \mathrm{E}$ staining was performed to investigate the pathological 

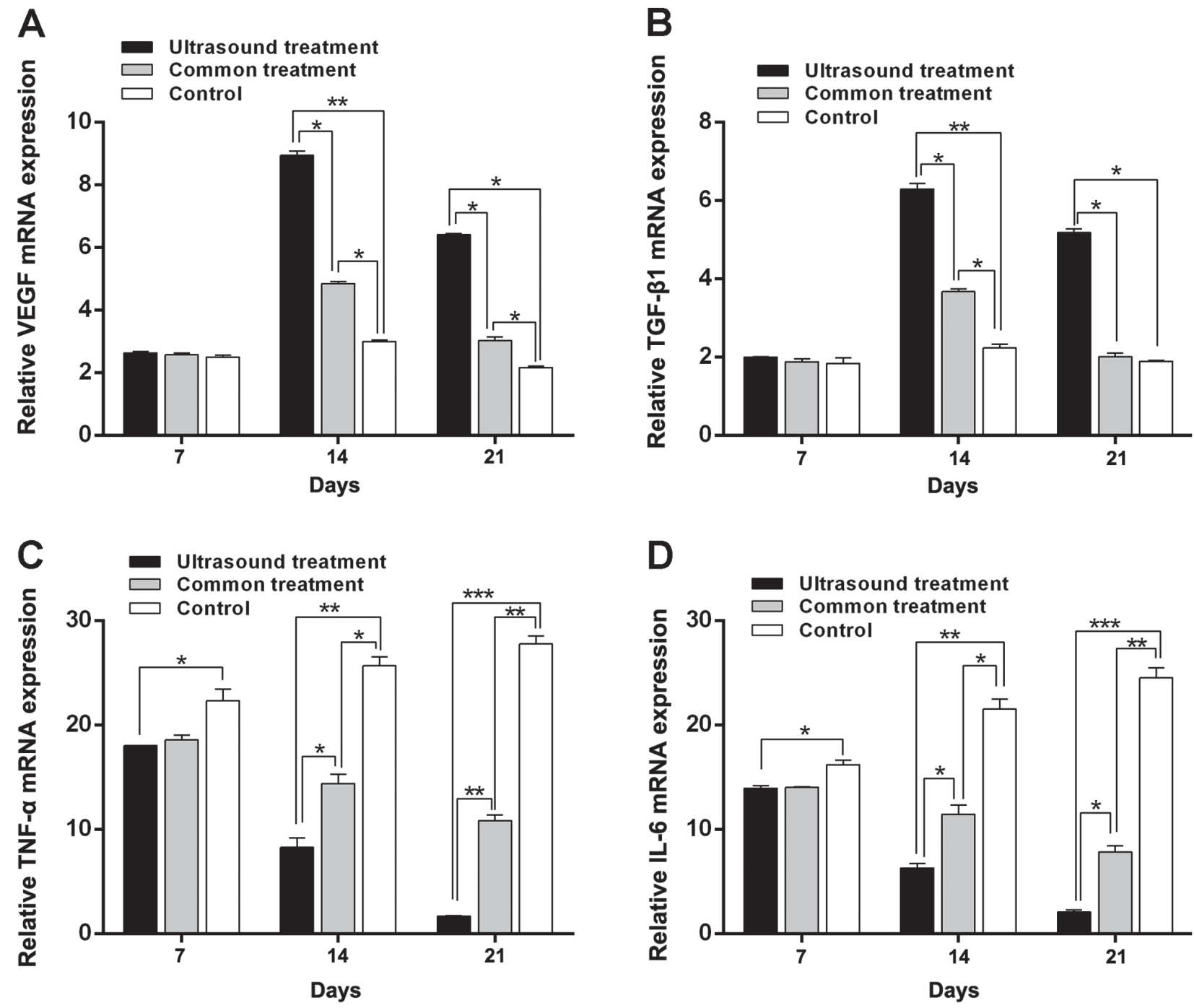

Figure 3. Reverse transcription-quantitative PCR results of VEGF, TGF- $\beta 1$, TNF- $\alpha$ and IL-6 in each group following treatment. The expression of (A) VEGF and (B) TGF- $\beta 1$ in the US group was significantly increased on the 14th day and 21st day compared with the control. Furthermore, as treatment time prolonged, the expression of (C) TNF- $\alpha$ and (D) IL-6 were gradually reduced in the US group, with the expression being lowest on the 21 st day. ${ }^{*} \mathrm{P}<0.05,{ }^{* *} \mathrm{P}<0.01$ and ${ }^{* * *} \mathrm{P}<0.001$ as indicated. VEGF, vascular endothelial growth factor; TGF- $\beta 1$, transforming growth factor- $\beta 1$; TNF- $\alpha$, tumor necrosis factor- $\alpha$; IL-6, interleukin-6; US, ultrasound.

changes that occurred in all treatment groups. The results obtained from the biopsy specimens collected from the wound margin revealed a marked inflammatory response occurring on the 7th day. As the treatment time was prolonged, the inflammatory response decreased, and when compared with the control, more fibroblasts, collagen fibers and neovascularization were observed in the rats of the US treatment group on days 14 and 21 (Fig. 2A). IHC analysis was performed to determine the role of VEGF (Fig. 2B) and TGF- $\beta 1$ (Fig. 2C) in the wound healing process of diabetic rats. Following treatment at all times, the results indicated that the expression of TGF- $\beta 1$ and VEGF was significantly increased in the US treatment group compared with the control group. Expressions were also significantly increased in the US group compared with the common treatment group, and TGF- $\beta 1$ and VEGF levels in the common treatment group were higher compared with the control group. Furthermore, as the treatment time prolonged, the expression of TGF- $\beta 1$ and VEGF in the wound of US treated rats decreased on the 14th day, and the expres- sion of TGF- $\beta 1$ and VEGF then increased on the 21st day (Fig. 2B and C).

Low frequency US treatment upregulates the expression of $T G F-\beta 1$ and VEGF in diabetic rats. To further investigate the difference in expression of TGF- $\beta 1$ and VEGF in diabetic rats after receiving treatment, the mRNA and protein expression of these molecules was assessed in the wounds of diabetic rats via RT-qPCR and western blotting, respectively. The results revealed that on the 7th day, mRNA expression did not exhibit any marked difference among the three groups, except for the TGF- $\beta 1$. TGF- $\beta 1 \mathrm{mRNA}$ levels did not exhibit any marked differences among the three groups and TGF- $\beta 1$ protein expression in the US group was significantly increased when compared with the control group $(\mathrm{P}<0.05)$. However, the mRNA (Fig. 3) and protein (Fig. 4) expression of VEGF in the US group were significantly increased on the 14th day $(\mathrm{P}<0.01$ in both mRNA and protein) and 21st day $(\mathrm{P}<0.05$ in the mRNA and $\mathrm{P}<0.01$ in the protein) compared with the control group (Figs. 3A 
A
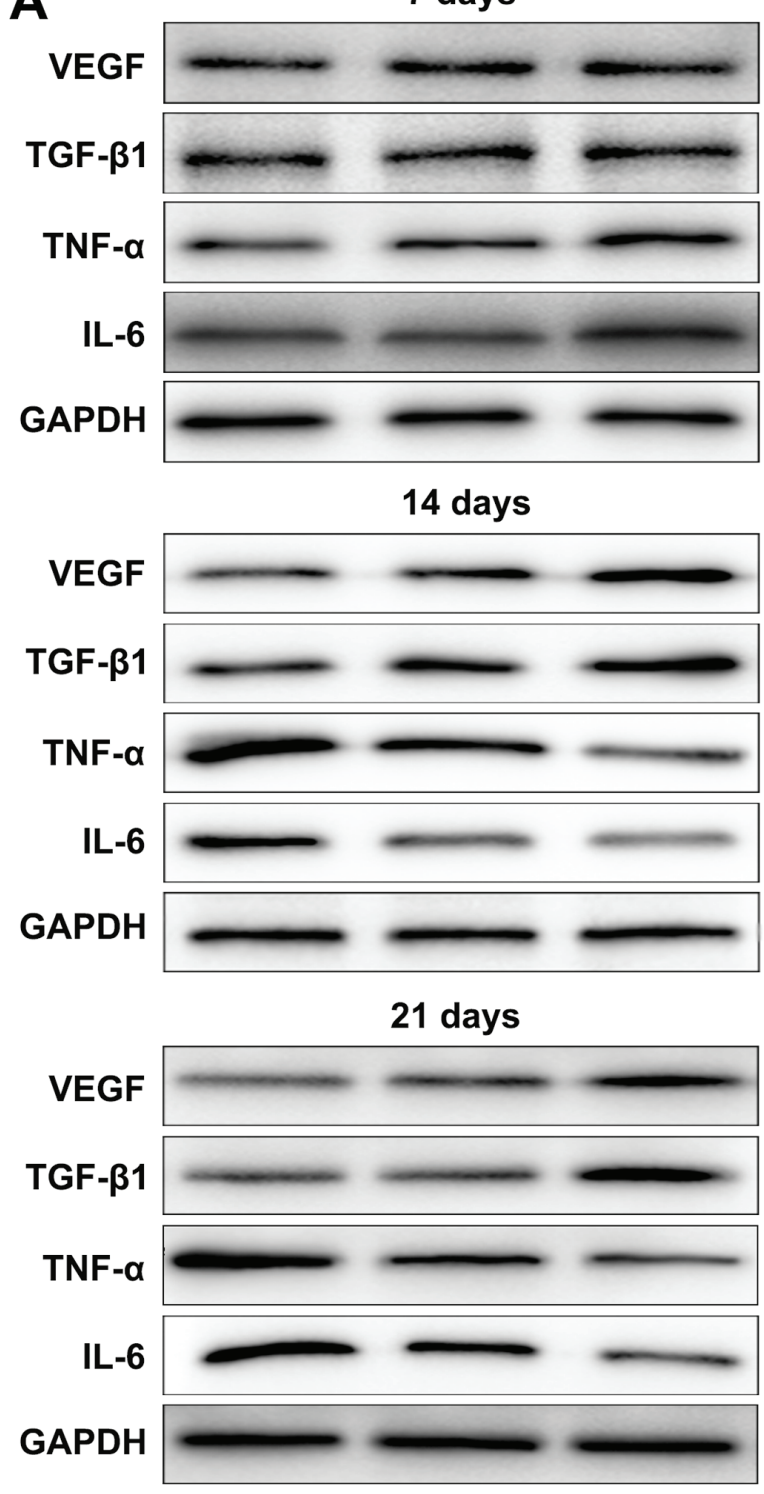

D
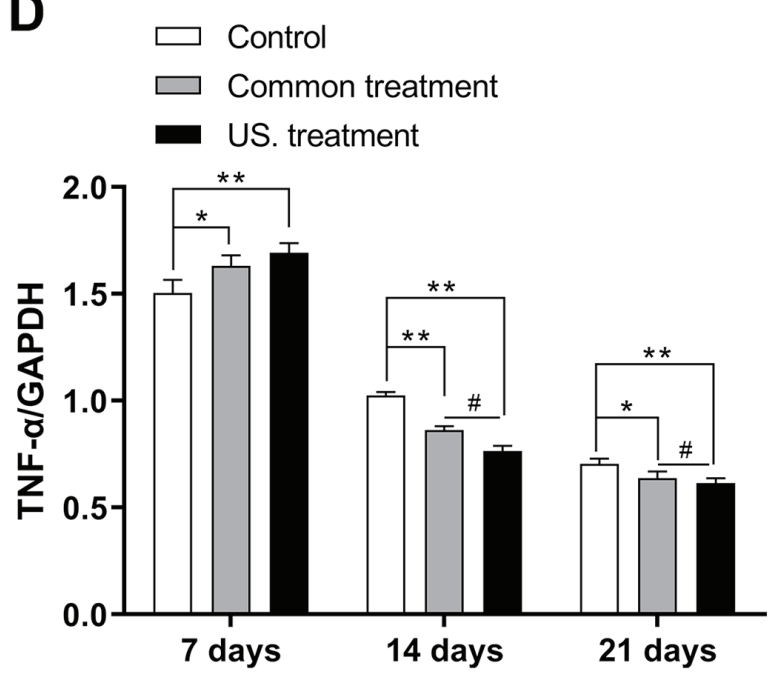

B
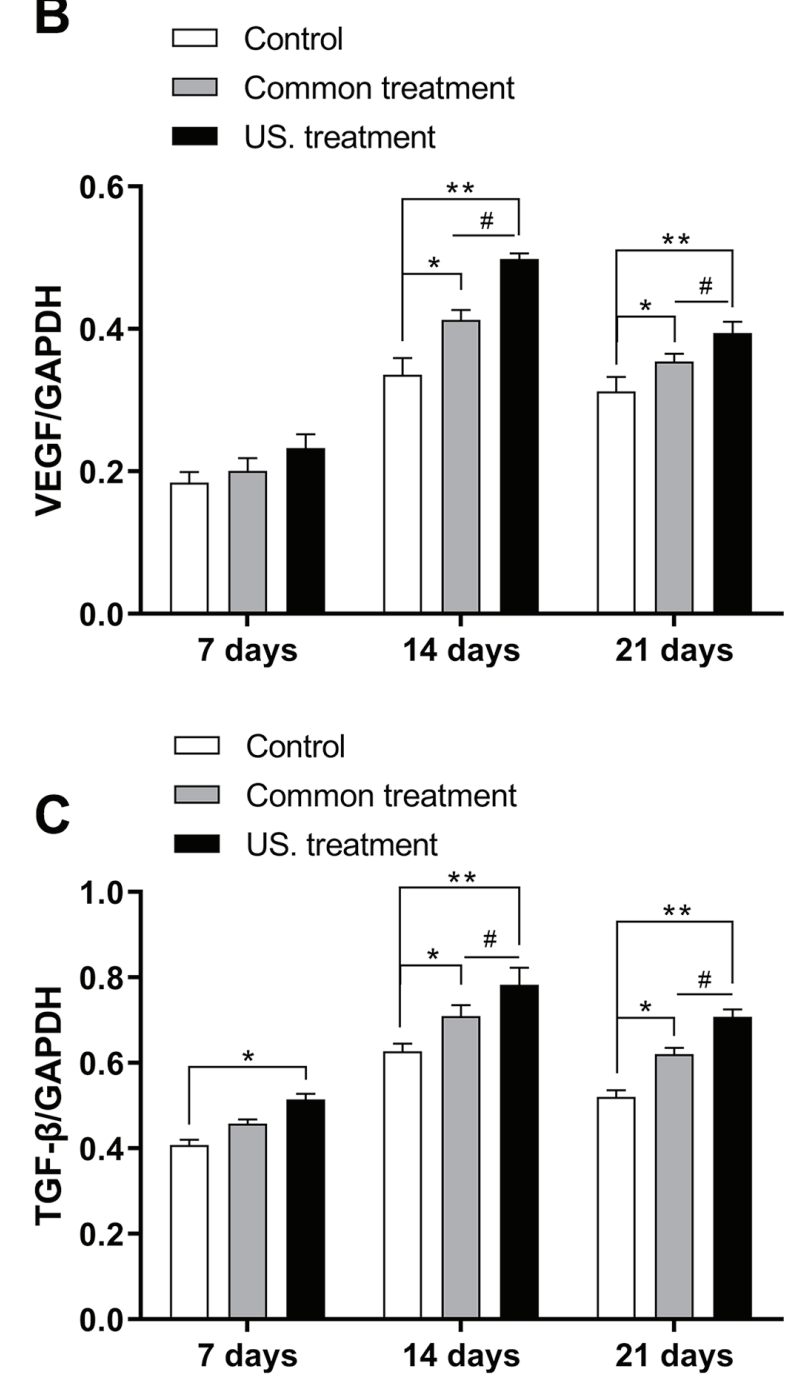

$\mathbf{E}$

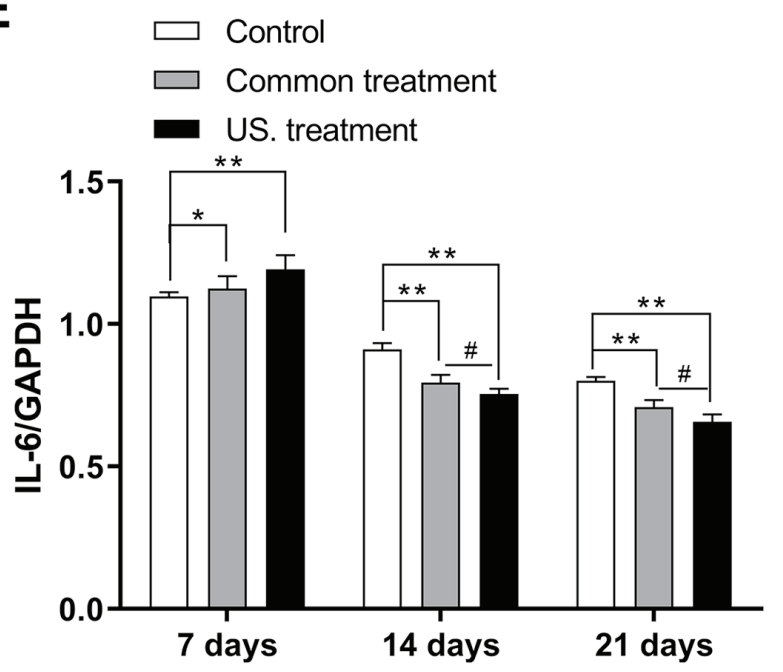

Figure 4. VEGF, TGF- $\beta 1$, TNF- $\alpha$ and IL-6 in each group were determined after treatment via western blotting. (A) The expression of the four proteins were determined using western blot analysis. (B) The expression of VEGF in the US treatment group was significantly increased on 14th and 21st day compared with the control group. (C) The expression of TGF- $\beta 1$ in the US treatment group was significantly increased on 14 th and 21 st day compared with the control group. (D) The expression of TNF- $\alpha$ in the US treatment group were gradually reduced, with the lowest expression level being exhibited on the 21 st day as treatment time was prolonged. (E) The expression of IL-6 in the US treatment group were gradually reduced, with the lowest expression level being exhibited on the 21 st day. ${ }^{*} \mathrm{P}<0.05$ and ${ }^{* *} \mathrm{P}<0.01$ as indicated; ${ }^{*} \mathrm{P}<0.05$ as indicated. VEGF, vascular endothelial growth factor; TGF- $\beta 1$, transforming growth factor- $\beta 1$; TNF- $\alpha$, tumor necrosis factor- $\alpha$; IL-6, interleukin-6; US, ultrasound. 
and 4A and B); the mRNA (Fig. 3) and protein (Fig. 4) expression of TGF- $\beta 1$ in the US group were significantly increased on the 14th day ( $\mathrm{P}<0.01$ in both mRNA and protein) and 21st day $(\mathrm{P}<0.05$ in the $\mathrm{mRNA}$ and $\mathrm{P}<0.01$ in the protein) compared with the control group (Fig. 3B and Fig. 4A-C); , and the common treatment group ( $\mathrm{P}<0.05$; Fig. $3 \mathrm{~A}$ and $\mathrm{B}$ and Fig. $4 \mathrm{~B}$ and $\mathrm{C})$. In addition, the mRNA and protein levels of TGF- $\beta 1$ and VEGF in the common treatment group were increased when compared with the control group $(\mathrm{P}<0.05)$. Furthermore, as treatment time prolonged, the mRNA and protein levels of TGF- $\beta 1$ and VEGF were markedly increased on the 14th day compared with the 7 th day. Levels then decreased on the 21st day compared with the 14th day.

Low-frequency US treatment suppresses the inflammatory response of diabetic rats. To confirm the effect of low-frequency US treatment on the inflammatory response of rats receiving treatment during the wound healing process, levels of IL-6 and TNF- $\alpha$ were determined via RT-qPCR and western blotting. As the treatment time was prolonged, the mRNA (Fig. 3) and protein (Fig. 4) levels of IL-6 and TNF- $\alpha$ in the US treatment group were reduced. The results were similar for the common treatment group. However, the mRNA and protein expression levels of IL- 6 and TNF- $\alpha$ in the control group were increased (Figs. 3C and D and 4D and E). Additionally, the mRNA and protein levels of IL- 6 and TNF- $\alpha$ in the US treatment group were lower compared with those in the control group on the 7 and 14th day (7th day, $\mathrm{P}<0.05$ in both TNF- $\alpha$ and IL-6; 14th day, $\mathrm{P}<0.01$ in both TNF- $\alpha$ and IL-6). The mRNA and protein levels of IL- 6 and TNF- $\alpha$ were the lowest compared with the control group on the 21st day $(\mathrm{P}<0.001$, Figs. $3 \mathrm{C}$ and $\mathrm{D}$ and $4 \mathrm{D}$ and $\mathrm{E}$ ). Furthermore, the mRNA expression of IL-6 and TNF- $\alpha$ in the US treatment group were significantly reduced compared with the common treatment group at day $14(\mathrm{P}<0.05$ in both TNF- $\alpha$ and IL-6) and $21(\mathrm{P}<0.01$ in the TNF- $\alpha$, and $\mathrm{P}<0.05$ in the IL-6; Fig. $3 \mathrm{C}$ and D); the protein expression of IL- 6 and TNF- $\alpha$ in the US treatment group were significantly reduced compared with the common treatment group at day 14 and 21 ( $\mathrm{P}<0.05$ in both TNF- $\alpha$ and IL-6; Fig. 4D and E).

\section{Discussion}

Diabetic patients often suffer from diabetic foot ulcers, occasionally requiring amputation, which severely affects patient health and poses a major socioeconomic burden to patients' families and society. Despite several interesting and promising experimental results, their application in the clinical setting has not been satisfactory to date. Hence, a novel and effective therapeutic method is urgently required. With advances in medical technology, previous studies have indicated that US treatment may promote the repair of various injuries, including bone, tendon, muscle, cartilage and ligament injuries (31-33). The results of the current study demonstrated that the wound healing rate of diabetic rats in the US treatment group $(85.62 \pm 4.16 \%)$ was higher compared with that in the other groups at 21 days after treatment, indicating that low-frequency US may enhance epithelialization and granulation tissue formation, thereby accelerating wound healing in diabetic rats. These effects may be mediated by decreasing the inflammatory response and promoting the production of growth factors.
The process of wound healing may be divided into inflammatory response, cell differentiation, cell proliferation and tissue repair stages (13). TNF- $\alpha$ and IL-6 serve a dual role by promoting as well as hindering wound healing (41). During the early stages of the inflammatory response, TNF- $\alpha$ and IL-6 promote the chemotaxis of inflammatory cells to remove necrotic tissues and pathogens, and promote the production and secretion of various cell growth factors including VEGF, basic fibroblast growth factor and IL-8 $(14,15)$, further accelerating the differentiation and proliferation of various repair cells, extracellular matrix formation and neovascularization, ultimately promoting wound healing (42). However, the continuation of the inflammatory response and overexpression of TNF- $\alpha$ and IL- 6 may cause the accumulation of harmful substances and severely impair granulation tissue formation and wound healing (43). The results of the present study demonstrated that the expression of IL-6 and TNF- $\alpha$ in US treatment group on the 7th, 14th and 21st day decreased with the time. However, the expression levels of IL- 6 and TNF- $\alpha$ in the control group were markedly increased compared with those determined on the first day. Additionally, as the treatment time was prolonged, the expression of IL- 6 and TNF- $\alpha$ in US treatment group was gradually downregulated. These results indicated that low-frequency US markedly inhibited the expression of IL- 6 and TNF- $\alpha$ in diabetic rats after treatment for 7 days and that their expression was gradually downregulated with increased treatment duration.

A number of studies have demonstrated that angiogenesis is the physiological basis of wound repair, which is regulated by cytokines via different signaling pathways that promote or inhibit wound healing $(37,38)$. VEGF is a soluble factor that is one of the key regulators of angiogenesis, which binds to the VEGF receptor to induce the proliferation and migration of vascular endothelial cells via autocrine and paracrine pathways, ultimately regulating neovascularization $(2,4,16,44)$. Additionally, TGF- $\beta 1$ serves a key role in wound healing by mediating the chemotaxis of inflammatory cells, the differentiation and proliferation of fibroblasts, and the production and degradation of collagen and extracellular matrix $(19,20,45)$. Decreased expression and dysfunction of TGF- $\beta 1$ and its receptors may hamper wound healing. In the present study, the results of IHC examination indicated that the expression of TGF- $\beta 1$ and VEGF was significantly increased in the US group compared with the control group. The highest result was observed on day 14 of US treatment, which subsequently decreased by day 21 . To further investigate whether low-frequency US promoted the expression of TGF- $\beta 1$ and VEGF, RT-qPCR and western blotting were performed. The results demonstrated that the mRNA expression of TGF- $\beta 1$ and the mRNA and protein expressions VEGF did not differ significantly among the three groups on day 7 . However, compared with the control group, the expression of TGF- $\beta 1$ and VEGF in the US treatment group were significantly increased on days 14 and 21. The results confirmed that low-frequency US increased the expression of TGF- $\beta 1$ and VEGF after treatment for 14 days, further promoting wound healing.

In conclusion, the present study indicated that low-frequency US increased the expression of TGF- $\beta 1$ and VEGF, induced the proliferation and differentiation of vascular endothelial cells and fibroblasts, and regulated the process of neovascularization in a diabetic rat model. Furthermore, it 
also reduced the expression of IL- 6 and TNF- $\alpha$ after treatment for 7 days and regulated and suppressed the abnormal inflammatory response, thereby accelerating wound healing in diabetic rats. Although the different effects of radiation on diabetic wound healing have been verified, the underlying mechanism of low frequency US in wound healing should be elucidated in following pharmacodynamic experiments.

\section{Acknowledgements}

Not applicable.

\section{Funding}

The present study was funded by the Scientific Research Foundation of the Education Department of Sichuan Province, China (grant no. 15ZB0186) and the Research and Development Program of North Sichuan Medical College (grant no. CBY13-A-ZP01).

\section{Availability of data and materials}

All data generated or analyzed during the present study are included in this published article.

\section{Authors' contributions}

LC conceived the current study, analyzed the majority of the data and wrote the initial draft of the manuscript. QZ, XC, JW and LW refined the study design, performed additional analyses and finalized the manuscript.

\section{Ethics approval and consent to participate}

The present study was approved by IRB of the Affiliated Hospital of North Sichuan Medical College Approval Notice (file no. $2016 \mathrm{ER}(\mathrm{A}) 022$ ).

\section{Patient consent for publication}

Not applicable.

\section{Competing interests}

All authors declare that they have no competing interests.

\section{References}

1. Cho NH, Shaw JE, Karuranga S, Huang Y, da Rocha Fernandes JD, Ohlrogge AW and Malanda B: IDF Diabetes Atlas: Globa estimates of diabetes prevalence for 2017 and projections for 2045. Diabetes Res Clin Pract 138: 271-281, 2018.

2. Kuo YR, Wang CT, Cheng JT, Kao GS, Chiang YC and Wang CJ: Adipose-derived stem cells accelerate diabetic wound healing through the induction of autocrine and paracrine effects. Cell Transplant 25: 71-81, 2016.

3. Zahedi A and Ebrahimi M: Statistical comments on 'The effect of foot exercise on wound healing in type 2 diabetes patients with a foot ulcer'. J Wound Ostomy Continence Nurs 45: 298, 2018.

4. Li G, Zou X, Zhu Y, Zhang J, Zhou L, Wang D, Li B and Chen Z: Expression and influence of matrix metalloproteinase-9/tissue inhibitor of metalloproteinase-1 and vascular endothelial growth factor in diabetic foot ulcers. Int J Low Extrem Wounds 16: 6-13, 2017.
5. Fernando ME, Seneviratne RM, Tan YM, Lazzarini PA, Sangla KS, Cunningham M, Buttner PG and Golledge J: Intensive versus conventional glycaemic control for treating diabetic foot ulcers. Cochrane Database Syst Rev: CD10764, 2016.

6. Corrêa MG, Gomes CM, Marques MR, Casati MZ, Nociti FH Jr and Sallum EA: Histometric analysis of the effect of enamel matrix derivative on the healing of periodontal defects in rats with diabetes. J Periodontol 84: 1309-1318, 2013.

7. Dumville JC, Deshpande S, O'Meara S and Speak K: Hydrocolloid dressings for healing diabetic foot ulcers. Cochrane Database Syst Rev: CD009099, 2012.

8. Berlanga-Acosta J, Fernández-Montequín J, Valdés-Pérez C Savigne-Gutiérrez W, Mendoza-Marí Y, García-Ojalvo A, Falcón-Cama V,García DelBarco-HerreraD,Fernández-MayolaM, Pérez-Saad H, et al: Diabetic foot ulcers and epidermal growth factor: Revisiting the local delivery route for a successful outcome. Biomed Res Int 2017: 2923759, 2017.

9. Lefrancois T, Mehta K, Sullivan V, Lin S and Glazebrook M: Evidence based review of literature on detriments to healing of diabetic foot ulcers. Foot Ankle Surg 23: 215-224, 2017.

10. Brantley JN and Verla TD: Use of placental membranes for the treatment of chronic diabetic foot ulcers. Adv Wound Care (New Rochelle) 4: 545-559, 2015.

11. Catrina SB and Zheng X: Disturbed hypoxic responses as a pathogenic mechanism of diabetic foot ulcers. Diabetes Metab Res Rev 32 (Suppl 1): S179-S185, 2016.

12. Adeghate J, Nurulain S, Tekes K, Fehér E, Kalász H and Adeghate E: Novel biological therapies for the treatment of diabetic foot ulcers. Expert Opin Biol Ther 17: 979-987, 2017.

13. Ferroni L, Gardin C, De Pieri A, Sambataro M, Seganfreddo E, Goretti C, Iacopi E, Zavan B and Piaggesi A: Treatment of diabetic foot ulcers with Therapeutic Magnetic Resonance $\left(\mathrm{TMR}^{\circledR}\right)$ improves the quality of granulation tissue. Eur J Histochem 61: $2800,2017$.

14. Tan L, Hou Z and Gao Y: Efficacy of combined treatment with vacuum sealing drainage and recombinant human epidermal growth factor for refractory wounds in the extremities and its effect on serum levels of IL-6, TNF- $\alpha$ and IL-2. Exp Ther Med 15: 288-294, 2018.

15. Basso FG, Pansani TN, Turrioni AP, Soares DG, de Souza CC and Hebling J: Tumor necrosis factor- $\alpha$ and interleukin (IL)-1 $\beta$, IL-6, and IL-8 impair in vitro migration and induce apoptosis of gingival fibroblasts and epithelial cells, delaying wound healing. J Periodontol 87: 990-996, 2016.

16. Zhou J, Ni M, Liu X, Ren Z and Zheng Z: Curcumol promotes vascular endothelial growth factor (VEGF)-mediated diabetic wound healing in streptozotocin-induced hyperglycemic rats. Med Sci Monit 23: 555-562, 2017.

17. Yoon D, Yoon D, Cha HJ, Lee JS and Chun W: Enhancement of wound healing efficiency mediated by artificial dermis functionalized with EGF or NRG1. Biomed Mater 13: 45007, 2018.

18. Zhengcai-Lou, Zihan-Lou and Yongmei-Tang: Comparative study on the effects of EGF and bFGF on the healing of human large traumatic perforations of the tympanic membrane. Laryngoscope 126: E23-E28, 2016.

19. Fekrazad R, Sarrafzadeh A, Kalhori KAM, Khan I, Arany PR and Giubellino A: Improved wound remodeling correlates with modulated TGF-beta expression in skin diabetic wounds following combined red and infrared photobiomodulation treatments. Photochem Photobiol 94: 775-779, 2018.

20. Abdoli A, Maspi N and Ghaffarifar F: Wound healing in cutaneous leishmaniasis: A double edged sword of IL-10 and TGF- $\beta$. Comp Immunol Microbiol Infect Dis 51: 15-26, 2017.

21. Karam RA, Rezk NA, Abdel Rahman TM and Al Saeed M: Effect of negative pressure wound therapy on molecular markers in diabetic foot ulcers. Gene 667: 56-61, 2018.

22. Lopes L, Setia O, Aurshina A, Liu S, Hu H, Isaji T, Liu H, Wang T, Ono S, Guo X, et al: Stem cell therapy for diabetic foot ulcers: A review of preclinical and clinical research. Stem Cell Res Ther 9: 188, 2018.

23. Chen CY, Wu RW, Hsu MC, Hsieh CJ and Chou MC: Adjunctive hyperbaric oxygen therapy for healing of chronic diabetic foot ulcers: A randomized controlled trial. J Wound Ostomy Continence Nurs 44: 536-545, 2017.

24. Asadi MR, Torkaman G, Hedayati M, Mohajeri-Tehrani MR, Ahmadi $M$ and Gohardani RF: Angiogenic effects of low-intensity cathodal direct current on ischemic diabetic foot ulcers: A randomized controlled trial. Diabetes Res Clin Pract 127: 147-155, 2017. 
25. Mills JL: Lower limb ischaemia in patients with diabetic foot ulcers and gangrene: Recognition, anatomic patterns and revascularization strategies. Diabetes Metab Res Rev 32 (Suppl 1): S239-S245, 2016.

26. Blume P and Wu S: Updating the diabetic foot treatment algorithm: Recommendations on treatment using advanced medicine and therapies. Wounds 30: 29-35, 2018.

27. Tardivo JP, Serrano R, Zimmermann LM, Matos LL, Baptista MS, Pinhal MAS and Atallah ÁN: Is surgical debridement necessary in the diabetic foot treated with photodynamic therapy? Diabet Foot Ankle 8: 1373552, 2017.

28. Campitiello F, Mancone M, Corte AD, Guerniero R and Canonico S: An evaluation of an ultrasonic debridement system in patients with diabetic foot ulcers: A case series. J Wound Care 27: 222-228, 2018.

29. Volpe P, Marcuccio D, Stilo G, Alberti A, Foti G, Volpe A, Princi D, Surace R, Pucci G and Massara M: Efficacy of cord blood platelet gel application for enhancing diabetic foot ulcer healing after lower limb revascularization. Semin Vasc Surg 30: 106-112, 2017.

30. Uysal S, Ozturk AM, Tasbakan M, Simsir IY, Unver A, Turgay N, Pullukcu H: Human myiasis in patients with diabetic foot: 18 cases. Ann Saudi Med 38: 208-213, 2018.

31. de Sousa ACT, da Rocha ÍBP, de Carvalho AFM, de Freitas Coelho NPM, Feitosa MCP, Barros EML, Arisawa EALS and de Amorim MRL: Comparative study between low level laser and therapeutic ultrasound in second intention ulcers repair in mice. J Lasers Med Sci 9: 134-138, 2018.

32. Liao AH, Hung CR, Chen $\mathrm{HK}$ and Chiang CP: Ultrasound-mediated EGF-coated-microbubble cavitation in dressings for wound-healing applications. Sci Rep 8: 8327, 2018.

33. Murphy CA, Houghton P, Brandys T, Rose G and Bryant D: The effect of $22.5 \mathrm{kHz}$ low-frequency contact ultrasound debridement (LFCUD) on lower extremity wound healing for a vascular surgery population: A randomised controlled trial. Int Wound J 15: 460-472, 2018

34. Sakamoto Y, Hojo M, Kosugi Y, Watanabe K, Hirose A, Inomata A, Suzuki T and Nakae D: Comparative study for carcinogenicity of 7 different multi-wall carbon nanotubes with different physicochemical characteristics by a single intraperitoneal injection in male Fischer 344 rats. J Toxicol Sci 43: 587-600, 2018.

35. Winter GD: Effect of air exposure and occlusion on experimental human skin wounds. Nature 200: 378-379, 1963.
36. Johnson LE, Larsen M and Perez MT: Retinal adaptation to changing glycemic levels in a rat model of type 2 diabetes. PLoS One 8: e55456, 2013.

37. Muhammad AA, Arulselvan P, Cheah PS, Abas F and Fakurazi S: Evaluation of wound healing properties of bioactive aqueous fraction from Moringa oleifera lam on experimentally induced diabetic animal model. Drug Des Devel Ther 10: 1715-1730, 2016.

38. Zhang XN, Ma ZJ, Wang Y, Sun B, Guo X, Pan CQ and Chen LM: Angelica Dahurica ethanolic extract improves impaired wound healing by activating angiogenesis in diabetes. PLoS One 12: e0177862, 2017.

39. Jerić M, Vukojević K, Vuica A and Filipović N: Diabetes mellitus influences the expression of NPY and VEGF in neurons of rat trigeminal ganglion. Neuropeptides 62: 57-64, 2017.

40. Livak KJ and Schmittgen TD: Analysis of relative gene expression data using real-time quantitative PCR and the 2(-Delta Delta C(T)) method. Methods 25: 402-408, 2001.

41. Yan SF, Yan SD, Ramasamy R and Schmidt AM: Tempering the wrath of RAGE: An emerging therapeutic strategy against diabetic complications, neurodegeneration, and inflammation. Ann Med 41: 408-422, 2009.

42. Sun M, He Y, Zhou T, Zhang P, Gao J and Lu F: Adipose extracellular matrix/stromal vascular fraction gel secretes angiogenic factors and enhances skin wound healing in a murine model. Biomed Res Int 2017: 3105780, 2017.

43. Patel S, Maheshwari A and Chandra A: Biomarkers for wound healing and their evaluation. J Wound Care 25: 46-55,2016.

44. Tsai JL, Lee YM, Pan CY and Lee AY: The novel VEGF121-VEGF165 fusion attenuates angiogenesis and drug resistance via targeting VEGFR2-HIF-1 $\alpha$-VEGF165/Lon signaling through PI3K-AKT-mTOR pathway. Curr Cancer Drug Targets 16: 275-286, 2016.

45. Ishii T, Uchida K, Hata S, Hatta M, Kita T, Miyake Y, Okamura K, Tamaoki S, Ishikawa $\mathrm{H}$ and Yamazaki J: TRPV2 channel inhibitors attenuate fibroblast differentiation and contraction mediated by keratinocyte-derived TGF- $\beta 1$ in an in vitro wound healing model of rats. J Dermatol Sci 90: 332-342, 2018.

(i) () $($ This work is licensed under a Creative Commons

cc) Atribution-NonCommercial-NoDerivatives 4.0 International (CC BY-NC-ND 4.0) License. 